\title{
Strength correlation between individual block, prism and basic wall panel for load bearing interlocking mortarless hollow block masonry
}

\begin{abstract}
This paper focuses on the development of the compressive strength correlation between the individual block, prism and basic wall panel for load bearing interlocking hollow mortarless blocks. The interlocking blocks used were developed by the Housing Research Centre at Universiti Putra Malaysia. The blocks consisted of stretcher, corner and half blocks. Forty individual block units from each type were tested under compression. The compressive strengths of 10 prisms assembled by stacking two stretcher blocks and two half blocks were evaluated. In addition, four wall panels each having a dimension of $1.2 \times 1.2 \mathrm{~m}$ were assembled and tested under axial compressive loads. The results obtained were compared with those found in bonded masonry. BS 5628 Part 1:1992 were used for predicting of the compressive capacity of the bonded masonry. The interlocking mechanism, crack patterns and failure mechanism of the interlocking masonry specimens are highlighted and discussed. The correlations between the compressive strength of the interlocking masonry individual block (fcb), prism (fcp) and standard panel (fcw) found in this analysis were $f c p=0.47 \mathrm{fcb}$, $\mathrm{fcw}=0.83 \mathrm{fcp}$ and $\mathrm{fcw}=0.39 \mathrm{fcb}$. Test results indicate that the interlocking mechanism and strength of the block in the load-bearing wall was satisfactory.
\end{abstract}

Item Type: Article 